\title{
The Optical, Electrical and Surface Differences between As-Deposited and Annealed NiO Films Produced by Ultrasonic Spray Pyrolysis
}

\author{
Olcay GENÇYILMAZ ${ }^{1}$, Ferhunde ATAY ${ }^{2}$, İdris AKYÜZ ${ }^{2}$ \\ ${ }^{I}$ Çankirl Karatekin University, Physics Department, Çankirl, Türkiye \\ ${ }^{2}$ Eskişehir Osmangazi University, Physics Department, Eskişehir, Türkiye
}

\begin{abstract}
The interest in $\mathrm{NiO}$ films has been growing fast due to their importance in many applications in science and technology. $\mathrm{NiO}$ films are an attractive material and are used common application area such as an antiferromagnetic layer, p-type transparent conducting film, electrochromic devices and chemical sensors. Also, $\mathrm{NiO}$ is a good candidate for p-type semiconductor films due to its wide band gap energy from 3.6 to $4.0 \mathrm{eV}$. In this work, $\mathrm{NiO}$ films have been grown on glass substrates by ultrasonic spray pyrolysis technique using $\mathrm{NiCl}_{2} \cdot 6 \mathrm{H}_{2} \mathrm{O}$ as spraying solution. Films have been annealed at $500{ }^{\circ} \mathrm{C}$ in air during $1 \mathrm{~h}$. Optical measurements of $\mathrm{NiO}$ film have been carried out at room temperature using a UV-VIS spectrophotometer. Band gap of as-deposited and annealed films have been calculated by using optical method and found as $3.67 \mathrm{eV}$ and $3.7 \mathrm{eV}$, respectively. Thicknesses of the films have been determined by filmetrics thin film measurement system. Surface properties of the films have been investigated with an atomic force microscope and electrical resistivity measurements have been performed by a four probe set-up. Consequently, the optical, electrical and surface differences have been determined between as-deposited and annealed $\mathrm{NiO}$ films produced by ultrasonic spray pyrolysis.
\end{abstract}

Keyword: NiO films, Atomic force microscopy, four-probe method, band gap.

\section{Introduction}

Transparent conductive oxide films, such as fluorine doped tin oxide (FTO), indium tin oxide (ITO), zinc oxide, etc. [1], are widely used for technological applications; all these films are n-type semiconductors. $\mathrm{NiO}$ is one of these oxides and last years, a growing interest has been devoted to nickel oxide thin films [2-10]. It is an interesting material for use as an antiferromagnetic layer [11], p-type transparent conducting film [12], in electrochromic devices [13] and functional sensor layer for chemical sensors [14]. Also, $\mathrm{NiO}$ is a good example of p-type semiconductor and its wide band gap energy from 3.6 to $4.0 \mathrm{eV}[15,16]$. Nowadays, transparent conducting thin film coatings of $p$ type semiconductors are required in different applications such as transparent electrodes for optoelectronic devices. NiO films can be produced using the methods such as thermal evaporation [17], sol-gel [18], sputtering [19,20], spray pyrolysis [21-23], anodic deposition [24]. Among these techniques, the spray pyrolysis technique is an attractive low cost, reproducible, simple, economic, allow doping of different elements and deposition onto large-areas without the need for vacuum and versatile method for synthesis of thin films. Generally produced films using these techniques are polycrystalline, stable, uniform, adherent and hard [25]. In accordance with this purpose, the $\mathrm{NiO}$ films were produced by spray pyrolysis. The $\mathrm{NiO}$ films were annealed at $500{ }^{\circ} \mathrm{C}$ in air during $1 \mathrm{~h}$. Studies on the effect of annealing temperature on the optical, electrical and surface properties and they are reported and discussed.

Sorumlu yazar/Corresponding author: Olcay GENÇYILMAZ Tel: 037621811 23,

e-posta: ogencyilmaz@karatekin.edu.tr, Gönderilme/Submitted:25.08.2014, Kabul/Accepted:11.02.2015 


\section{Experimental details}

\subsection{Formation of $\mathrm{NiO}$ films}

$\mathrm{NiO}$ films were produced onto glass substrates (Objekttrager, $1 \mathrm{~cm} \times 1 \mathrm{~cm}$ ) by spray pyrolysis technique at a substrate temperature of $300 \pm 5{ }^{\circ} \mathrm{C}$. The spraying solution contains $\mathrm{NiCl}_{2} \cdot 6 \mathrm{H}_{2} \mathrm{O}$ solutions and deionized water was used as the solvent. The starting spraying solution was mixed and heated $\left(30^{\circ} \mathrm{C}\right)$ during $20 \mathrm{~min}$. with a magnetic mixer to prevent sedimentation. Details of other experimental parameters are given in Table 1. Schematic diagram of the spray pyrolysis set up is shown in Fig. 1.

The ultrasonic oscillator frequency was $100 \mathrm{kHz}$, and the droplet size was $20 \mu \mathrm{m}$. The glass substrates were heated by an electrical heater and the substrate temperature was measured using a chromel-alumel thermocouple. The solution flow rate was kept at $5 \mathrm{cc} . \mathrm{min}^{-1}$ by a flowmeter. Air was used as the carrier gas (1 bar) and the electrical contacts were made by silver paint. $\mathrm{NiCl}_{2} \cdot 6 \mathrm{H}_{2} \mathrm{O}$ solution was sprayed onto glass substrates at $300 \pm 5{ }^{\circ} \mathrm{C}$ temperature, therefore resulting in the formation of $\mathrm{NiO}$ film according to the following reaction:

$$
\mathrm{NiCl}_{2} \cdot 6 \mathrm{H}_{2} \mathrm{O} \rightarrow \mathrm{NiO}+2 \mathrm{HCl} \uparrow+5 \mathrm{H}_{2} \mathrm{O} \uparrow
$$

The as-deposited films were gray in color adherent to the substrate.

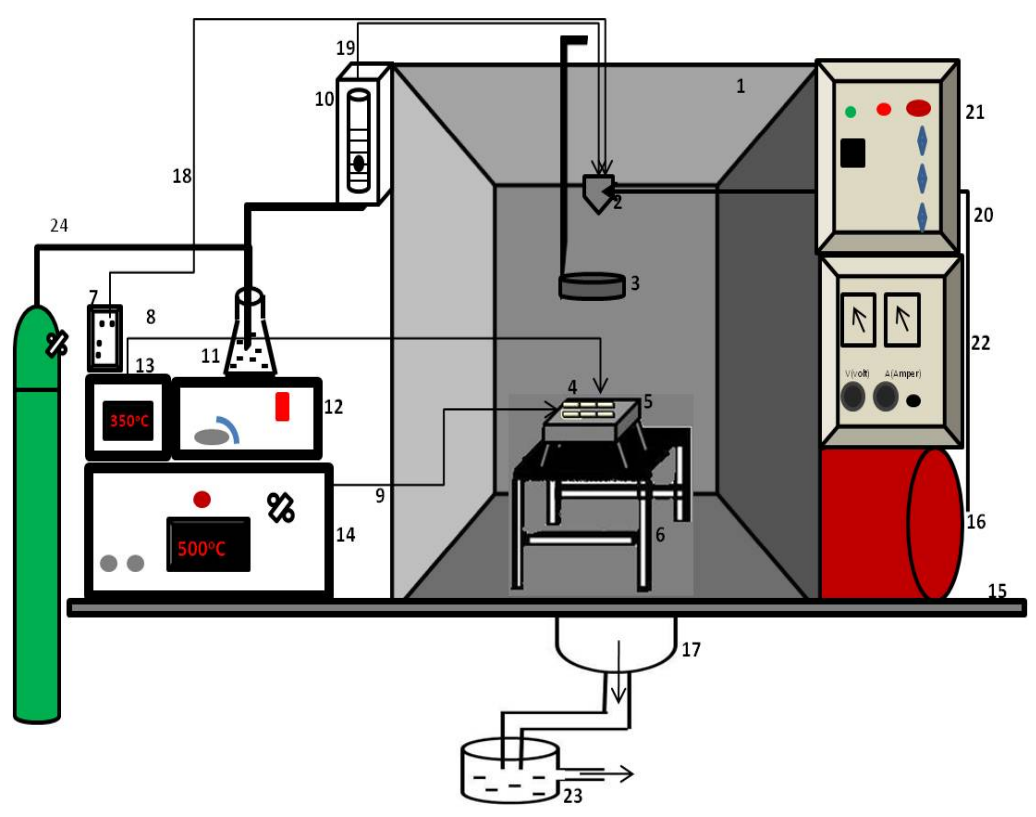

Fig. 1. (1) Spraying chamber, (2) Ultrasonic atomizer, (3) Moving pan (4) Glass substrates (5) Bronze block (5000-6000 Watt), (6) Moving base, (7) Oscillator, (8) 1. termocouple, (9) 2. termocouple, (10) Flowmeter, (11) Spraying solution, (12) Heater-magnetic mixer, (13) Temperature indicator, (14) Electrical heater, (15) Table, (16) $\mathrm{N}_{2}$ tube, (17) Fan, (18) Cable of oscillator, (19) Spraying hose, (20) Air hose, (21) ac ampermeter (22) ac voltmeter, (23) water-filled container (24)Nitrogen gas. 
Table 1. Details of experimental parameters used to produce NiO films.

\begin{tabular}{ll}
\hline Material & $\mathrm{NiO}$ and Annealed NiO \\
Sample Code & $\mathrm{NiO}$ \\
& $\mathrm{NiO}-$ Annealed \\
Anneling Time/Temperature & $1 \mathrm{~h} / 500{ }^{\circ} \mathrm{C}$ \\
Source Solution & $\mathrm{NiCl}_{2} \cdot 6 \mathrm{H}_{2} \mathrm{O}$ \\
Molarity & $0.1 \mathrm{M}$ \\
Total volume of spray solution & $100 \mathrm{~cm}^{3}$ \\
Substrate Temperature & $300 \pm 5^{\circ} \mathrm{C}$ \\
Solution flow rate & $5 \mathrm{~cm}^{3} \mathrm{~min}^{-1}$ \\
Spraying time & $20 \mathrm{~min}$ \\
Nozzle to substrate distance & $25 \mathrm{~cm}$ \\
Carrier gas/pressure & $1 \mathrm{Air} / \mathrm{bar}$ \\
\hline
\end{tabular}

\subsection{Characterization techniques}

The thicknesses of the films were measured using filmetrics thin film measurement system. The thickness of the films was determined as 0.76 and $0.67 \mu \mathrm{m}$ and these values are given in Table 3. The optical transmittance and absorbance spectra of the films were taken from a Schimadzu UV-2550 UV-VIS spectrophotometer, and the optical energy gaps of the films were calculated using the optical method. The resistivity measurements were made using a Keithley 2601 A System SourceMeter Four-probe set up. Besides, the surface properties of the films were examined using Park System XE 70 model -AFM atomic force microscopy.

\section{Results and discussion}

Annealing process and substrate temperature have been an important effect on the deposited films some properties such as optical, surface and electrical properties. Optical transmittance and absorbance spectra of the $\mathrm{NiO}$ films which were recorded in the wavelength range of $300-800 \mathrm{~nm}$ are shown in Fig. 2. The films exhibit a high average transmittance $(\sim 50 \%)$ in the visible region. This suggests that these films indicate a good optical quality due to low scattering or absorption losses. It is clear from Fig. 2 (a) that annealed $\mathrm{NiO}$ films caused and increase in transmittance values. The average value of transmittance of the $\mathrm{NiO}$ films also increased with annealing process from $\sim 46 \%$ to $\sim 57 \%$ in the visible region depending on the annealing processes. Decreasing of thickness may be a reason for the increase in transmittance values of samples annealed for 1 hour. Similar results have been reported by Cattin et al. [26]. Annealing process has also been an important effect on the surface properties of $\mathrm{NiO}$ films as can be seen from our AFM images (Fig. 5). So, the improvement of the transmittance for annealed $\mathrm{NiO}$ films could be related to decrease in optical scattering processes after annealed. This kind of effect has been reported by Boukhachem et al. [27].

In addition, we can see from Fig. 2 (b) that the absorption edge has been changed after the annealing process. The sharp absorption edges can be clearly observed with the increases of 
the annealing process as shown in Fig. 2 (b). Also, sharp absorption edges can be clearly observed and shift to the shorter wavelength after the annealing process as shown in Fig. 2 (b). We think that our as-deposited $\mathrm{NiO}$ films have deformation and defects near band edges. Annealing process may probably lead to decreasing of such deformations and resulted with a sharper absorption edge. This will also cause the optical band values to increase as can be seen from Fig. 3.

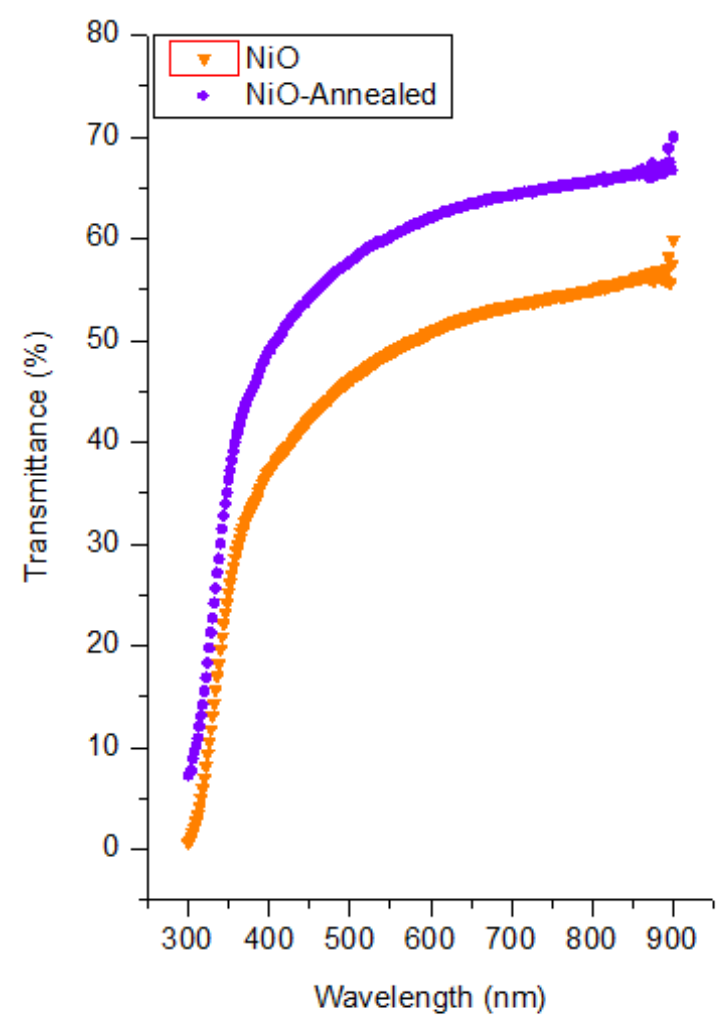

(a)

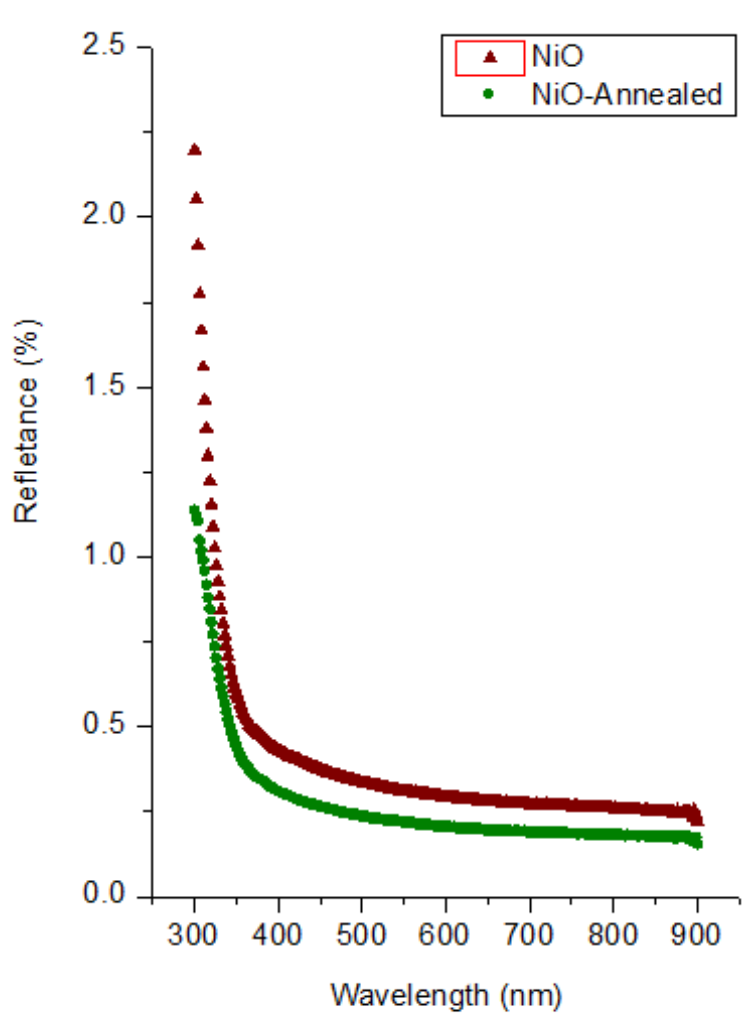

(b)

Fig. 2. (a) The transmittance and (b) absorbance spectra of the NiO films.

There are reports where the electronic transitions from valence band toward conduction band are analyzed as direct electronic transitions or as indirect electronic transitions. In general, the values of the optical band gap calculated considering direct allowed electronic transition or indirect electronic transition show a high dispersion in the energy range from 3.4 to $3.8 \mathrm{eV}$ [28]. The dependence of absorption coefficient on photon energy in the high absorption regions is carried out to obtain the detailed information about the energy band gaps. The relation between absorption coefficient and photon energy is expressed as follows [29];

$$
(\alpha h v)=A\left(h v-E_{g}\right)^{n}
$$

where $A$ is an energy-independent constant, $E_{g}$ is the optical band gap, $\mathrm{n}$ is an index that characterizes the optical absorption process and it is theoretically equal to 2 and $1 / 2$ for indirect and direct allowed transitions, respectively. It is well known that direct transition across the band gap is feasible between the valence and the conduction band edges in $k$ space. 
In the transition process, the total energy and momentum of the electron-photon system must be conserved [29]. Fig. 3 shows the plots of $(\alpha h v)^{2}$ vs. photon energy for the films. We observed a uniform change from $3.47 \mathrm{eV}$ to $3.7 \mathrm{eV}$ in the $E_{g}$ values with annealing. These change result from annealing process that is a good agreement in the literature [26].

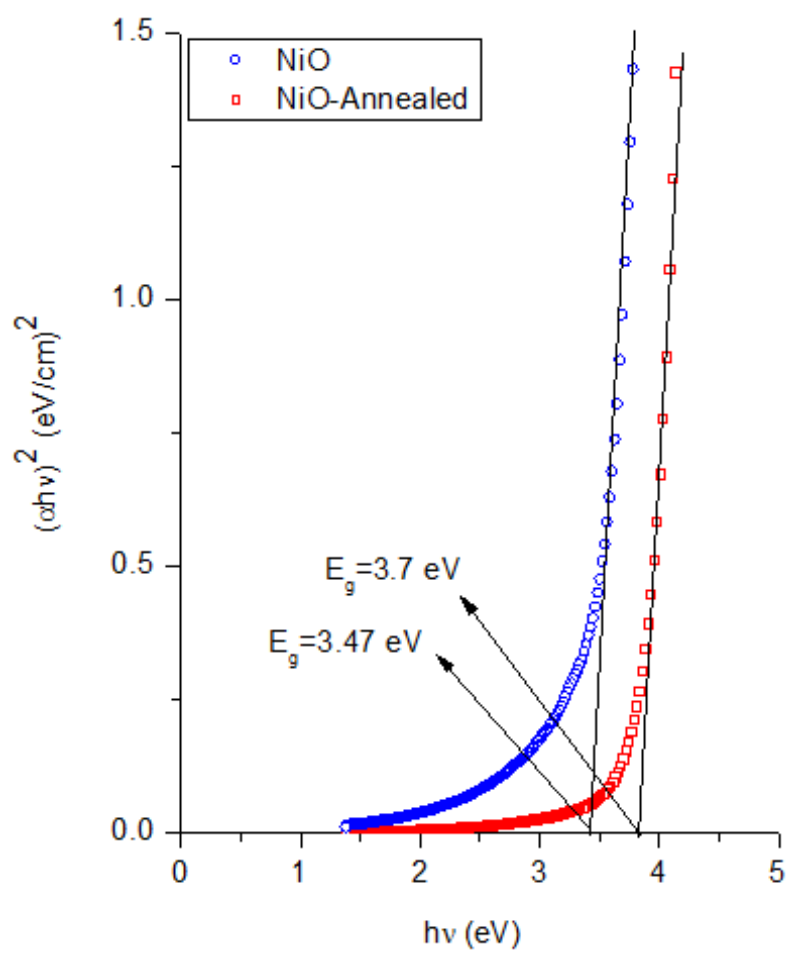

Fig 3. The plot of $(\alpha h v)^{2}$ vs. photon energy and inset of the graph Urbach plots of the $\mathrm{NiO}$ films.

The absorption edge can be determined from the exponential dependence of the absorption coefficient and it is determined as [30]

$$
(\alpha h v)=\alpha_{0} \exp \left(h v / E_{u}\right)
$$

where $\alpha_{0}$ is a constant and $E_{u}$ is the Urbach energy. Plotting the dependence of $\ln \alpha$ vs. $h v$ as shown in Fig 4 should give a straight line. Thus, a plot of $\operatorname{In}[\alpha(\lambda)]$ versus photon energy should be linear and Urbach energy can be obtained from the slope. The $\operatorname{In}[\alpha(\lambda)]$ versus photon energy plots for the $\mathrm{NiO}$ and $\mathrm{NiO}$-annealed films at are shown in Fig. 4.

Urbach energy was calculated from the reciprocal gradient of the linear portion of these curves and was determined for the $\mathrm{NiO}$ and $\mathrm{NiO}$-annealed films as $124 \mathrm{meV}$ and $150 \mathrm{meV}$, respectively. Urbach energy increases slightly due to the width of the band tail increases with the annealing process. We think that thermal induced structural disorder of the film increases with the annealing process, which leads to a degradation of the $\mathrm{NiO}$ films. These results fundamentally agree with the analysis results of the shift of the optical absorption edge. 


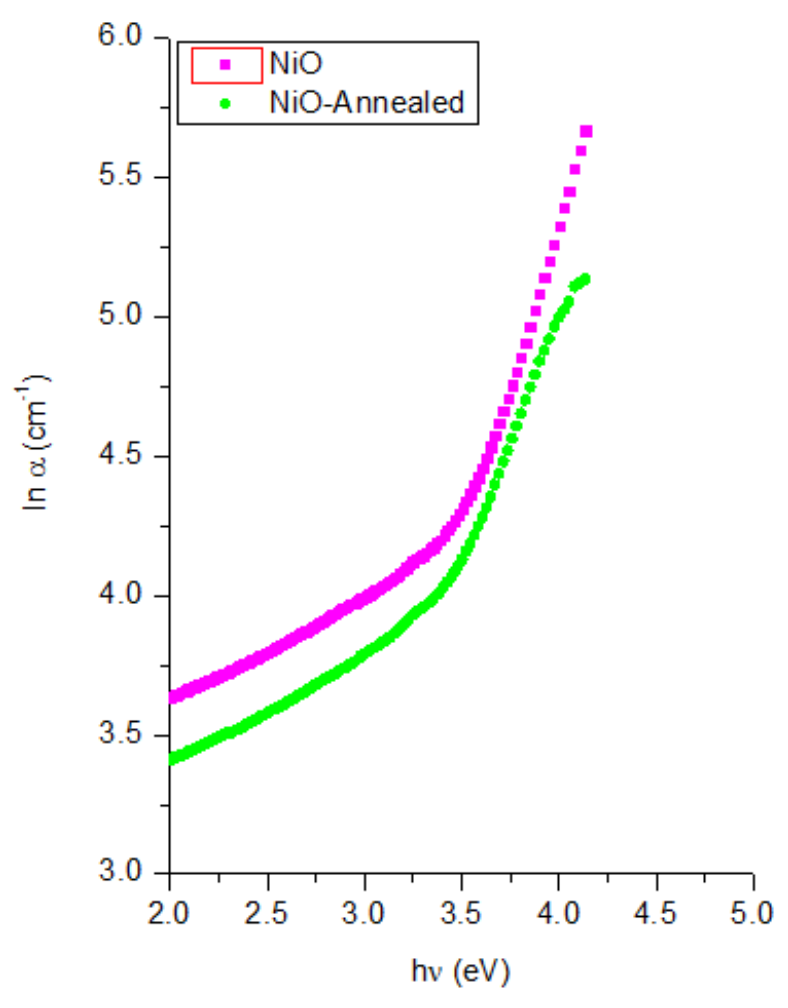

Fig. 4. The Urbach plots of $\mathrm{NiO}$ films

Fig. 5 shows AFM images of $\mathrm{NiO}$ films. The influence of annealing can be easily seen from these figures. A granular and sharp structure with grains in different sizes is dominant for $\mathrm{NiO}$ films. White regions in this figure represent the formation of agglomerated grains one on the top of the other. For these white regions, we think that neighboring grains come together forming large clusters. So, grains in the white regions are larger in size as compared to others. From all of these interpretations, film growth mechanism is thought to be formed firstly layer by layer and then island growth type (mixed growth). It was determined from AFM images of $\mathrm{NiO}$ films that there are also black regions which represent the grain cavities on the film surface. Probably, atoms coming to the surface do not prefer these regions as growth centers and migrate to the white regions with bigger atom groups by surface diffusion.

Also, the glass substrate has roughness on its surface. Regions on the substrate surface such as hollows, valleys and step outsets behave like a high energy barrier for the atoms which tend to leave from the surface. So, these are appropriate regions where defects and atoms of the film tend to nucleate. Thus, the substrate also affects the homogeneity of the surface and size of the grains. $\mathrm{NiO}$ showed itself as a decrease in the agglomerated regions with annealing process, which in turn increases the grain cavities. We can conclude that, annealing process has a dramatic effect on the surface properties of the films, especially for the annealed-NiO films. Consequently; the surface morphology of annealed-NiO films has the best of granular structure. $R_{q}$ (root mean square), $R_{a}$ (average) and $R_{p v}$ (peakvalley) values of $\mathrm{NiO}$ films are given in Table 2 . It is clear that annealing affected the roughness values of $\mathrm{NiO}$ films and roughness values of the films decreased with annealing process. 


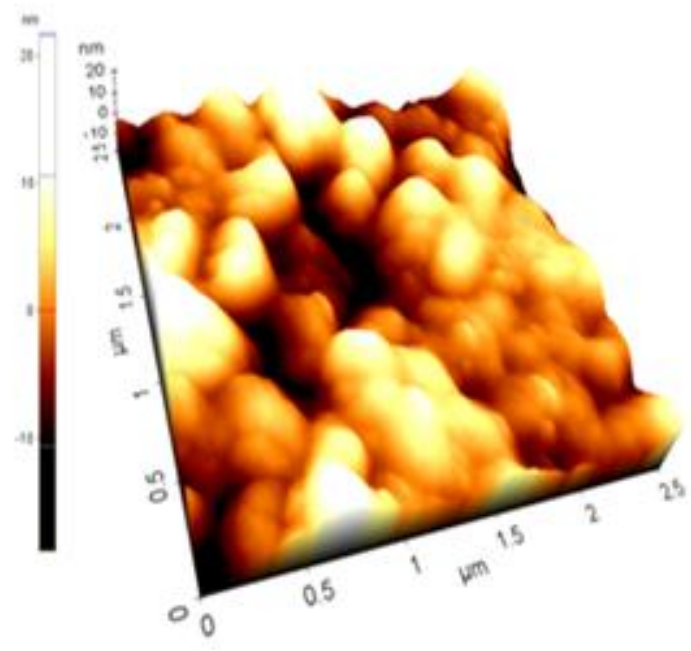

(a)

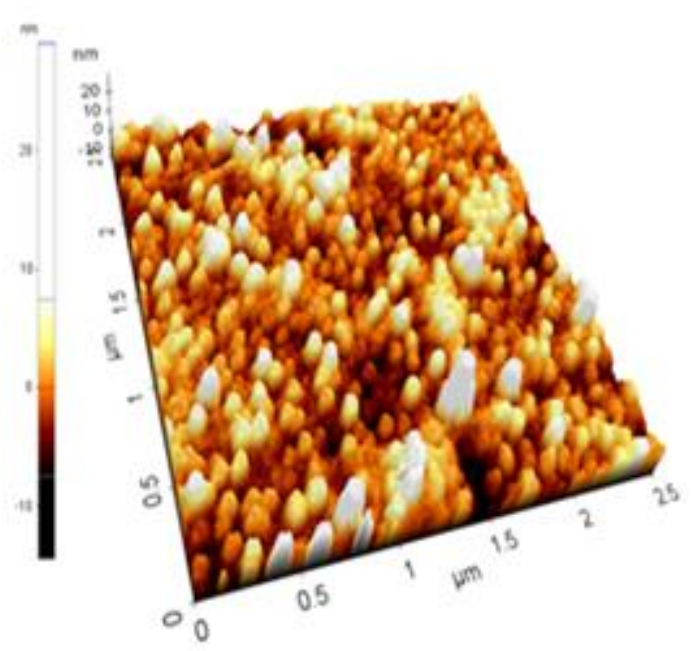

(b)

Fig 5. AFM images of (a) $\mathrm{NiO}$ and (b) annealed-NiO films.

Table 2. $\mathrm{R}_{\mathrm{q}}, \mathrm{R}_{\mathrm{a}}$ and $\mathrm{R}_{\mathrm{pv}}$ roughness values of $\mathrm{NiO}$ films.

\begin{tabular}{|c|c|c|c|}
\hline Material & $\mathrm{R}_{\mathrm{pv}}(\mathrm{nm})$ & $\mathrm{R}_{\mathrm{q}}(\mathrm{nm})$ & $\mathrm{R}_{\mathrm{a}}(\mathrm{nm})$ \\
\hline $\mathrm{NiO}$ & 46.335 & 5.124 & 4.112 \\
\hline NiO-Annealed & 29.256 & 3.658 & 2.741 \\
\hline
\end{tabular}

The electrical resistivity of $\mathrm{NiO}$ films were measured using four-probe technique. The results are shown in Table 3, as it can be seen, the electrical resistivity decreases as annealing process. The electrical resistivity changes by two orders of magnitude approximately (from $10^{4}$ to $\left.10^{2} \Omega . \mathrm{cm}\right)$. It is well known that oxygen tends to site at grain bound barriers in polycrystalline films both at grain boundaries and also on the surface. These oxygen spaces may produce potential barrier for charge carriers [31-33]. So, we think that this change is due to the decreasing oxygen deficiencies because of the micro structural compositional change of the grains, in addition to other phenomena such as disorder and defects at the grainboundaries.

Table 3. Electrical resistivity and thickness values of $\mathrm{NiO}$ films.

\begin{tabular}{|c|c|c|}
\hline Material & $\mathrm{d}(\mu \mathrm{m})$ & $\rho(\Omega . \mathrm{cm})$ \\
\hline $\mathrm{NiO}$ & 0.76 & $1.64 \times 10^{4}$ \\
\hline NiO-Annealed & 0.67 & $7.82 \times 10^{2}$ \\
\hline
\end{tabular}




\section{Conclusion}

In this work, the effect of annealing on the optical, electrical and surface properties of ultrasonically sprayed $\mathrm{NiO}$ films has been investigated. Firstly, the results of the electrical properties of $\mathrm{NiO}$ films depending on annealing process were presented. The electrical resistivity values reduced electrical resistivity from $10^{4}$ to $10^{2} \Omega \mathrm{cm}$ with annealing process. It was determined that $\mathrm{NiO}$ has a rather high resistivity and annealing made a notable decrease on this high-resistivity value. This is a very desirable property for many technological applications. Also, the transmittance values of $\mathrm{NiO}$ films were increased by annealing process. The optical band gap energy values which were determined by using optical method increase from 3.47 to $3.7 \mathrm{eV}$. Also, it was seen from AFM images that the most homogeneous surface was seen in annealed-NiO films and their morphologies changed considerably with annealing process. The obtained results indicate that the annealing process changes the optical, electrical and surface properties of the $\mathrm{NiO}$ films.

\section{References}

[1] Chopra, K.L., Major, S., Pandya, D.K., (1983). Transparent conductors-A status review. Thin Solid Films, 102(1), 1-46.

[2] He, J., Lindström, H., Hagfeldt, A., Lindquist, S.E., (1999). Dye-Sensitized Nanostructured p-Type Nickel Oxide Film as a Photocathode for a Solar Cell. Journal of Physics and Chemistry B, 103, 8940-8943.

[3] Boschloo, G., Hagfeldt, A., (2001). Spectroelectrochemistry of Nanostructured NiO. Journal of Physics and Chemistry B, 105, 3039-3044.

[4] Lu, Y.M., Hwang, W.S., Yang, J.S., (2002). Effects of substrate temperature on the resistivity of non-stoichiometric sputtered NiOx films. Surface Coating Technology,155, 231-235.

[5] Hotovy, I., Huran, J., Spiess, L., Liday, J., Sitter, H., Hascik, S., (2003). The influence of process parameters and annealing temperature on the physical properties of sputtered $\mathrm{NiO}$ thin films. Vacuum, 691, 237-242.

[6] Bandara, J., Divarathne, C.M., Nanayakkara, S.D., (2004). Corrigendum to "Fabrication of $n-p$ junction electrodes made of n-type $\mathrm{SnO}_{2}$ and p-type $\mathrm{NiO}$ for control of charge recombination in dye-sensitized solar cells. Solar Energy Materials and Solar Cells 81, 429-437.

[7] Chan, I.M., Hong, F.C., (2004). Improved performance of the single-layer and doublelayer organic light emitting diodes by nickel oxide coated indium tin oxide anode. Thin Solid Films, 450, 304-311.

[8] Penin, N., Rougier, A., Laffont, L., Poizat, P., Tarascon, J.M., (2006). Improved cyclability by tungsten addition in electrochromic NiO thin films. Solar Energy Materials and Solar Cells, 90, 422-433.

[9] Kamal, H., Elmaghraby, E.K., Ali, S.A., Abdel-Hady, K., (2005). The electrochromic behavior of nickel oxide films sprayed at different preparative conditions. Thin Solid Films 483, 330-339.

[10] Olivier, J., Servet, B., Vergnolle, M., Mosca, M., Garry, G., (2001). Stability/instability of conductivity and work function changes of ITO thin films, UV-irradiated in air or vacuum: Measurements by the four-probe method and by Kelvin force microscopy. Synthetic Met. 122, 87-89. 
[11] Fujii, E., Tomozawa, A., Torii, H., Takayama, R., (1996). Preferred Orientations of NiO Films Prepared by Plasma-Enhanced Metalorganic Chemical Vapor Deposition. Journal of Applied Physics, 35, L328-330.

[12] Sato, H., Minami, T., Takata, S., Yamada, T., (1993). Transparent conducting p-type $\mathrm{NiO}$ thin films prepared by magnetron sputtering. Thin Solid Films, 236 27-31.

[13] Kitao, M., Izawa, K., Urabe, K., Komatsu, T., (1994). Preparation and Electrochromic Properties of RF-Sputtered NiO Films Prepared in $\mathrm{Ar} / \mathrm{O}_{2} / \mathrm{H}_{2}$ Atmosphere. Japan Journal of Applied Physics, 33, 6656-6662.

[14] Kumagai, H., Matsumoto, M., Toyoda, K., Obara, M., (1996). Preparation and charactesictics nickel oxide thin film by controlled growth with sequential surface chemical reactions. Journal of Material Science Letters, 15, 1081-1083.

[15] Kunz, A.B., (1981). Electronic structure of NiO. Journal of Physics C. 14L, 445.

[16] Adler, D., Feinlei, J., (1970). Electrical and Optical Properties of Narrow-Band Materials. Physics Review B. 2, 3112.

[17] Dinescu, M., Verardi, P., (1996). ZnO thin film deposition by laser ablation of Zn target in oxygen reactive atmosphere. Applied Surface Science, 106, 149-158.

[18] Dakhel, A.A., Ali-Mohamed, A.Y., (2009). Structural, electrical, and optical absorption properties of $\mathrm{La}_{x} \mathrm{Cd}_{1-x} \mathrm{O}$ solid solution films obtained by sol-gel method. Materials Chemistry and Physics, 113, 356-360.

[19] Subramanyam T.K., Uthanna S., Sinivasulu Naidu B., (1998). Preparation and characterization of $\mathrm{CdO}$ films deposited by dc magnetron reactive sputtering. Materials Letters, 35, 214-220.

[20] Gurumurugan, K., Mangalaraj, D., Narayandass, Sa.K., (1996). Magnetron Sputtered Transparent Conducting CdO Thin Films. Journal of Electronic Materials, 25, 765-770.

[21] Gomez, M., Medina, A., Estrada, W. (2000). Improved electrochromic films of $\mathrm{NiO}_{x}$ and $\mathrm{WO}_{x} \mathrm{P}_{y}$ obtained by spray pyrolysis. Solar Energy Materials \& Solar Cells, 64, 297-309.

[22] Reguig, B.A., Khelil, A., Cattin, L., Morsli, M., Berne`de, J.C. (2007). Properties of NiO thin films deposited by intermittent spray pyrolysis process. Applied Surface Science, 253, 4330-4334.

[23] Yoshida, H., Deguchi, H., Kawano, M., Hashino, K., Inagaki, T., Ijichi, H., Horiuchi, M., Kawahara, K., Suda, S. (2007). Study on pyrolysing behavior of NiO-SDC composite particles prepared by spray pyrolysis technique. Solid State Ionics, 178, 399-405.

[24] Orel, Z.C. Hutchins, M.G. McMeeking, G. (1993). The electrochromic properties of hydrated nickel oxide films formed by colloidal and anodic deposition. Sol. Energy Mater. Sol. Cell, 30, 327-337.

[25] Vazquez Luna, J.G., Zehe, A., Zeleya-Angel, O., (1999). Chemical CdS thin-film deposition influenced by external electric and magnetic fields. Crystal Resreach Technology, 34, 949-958.

[26] Cattin, L., Reguig, B.A., Khelil, A., Morsli, M., Benchouk, K., J Berne`de, C., (2008). Properties of $\mathrm{NiO}$ thin films deposited by chemical spray pyrolysis using different precursor solutions. Applied Surface Science, 254, 5814-5821.

[27] Boukhackem, A., Boughalmi, R., Karyaoui, M., Chtourou, R., (2014). Study of substrate temperature effects on stuructural, optical, mechanical and opto-thermal properties of $\mathrm{NiO}$ sprayed semiconductor thin films. Material Science and Engineering B, 188, 72-77.

[28] Kamal, H., Elmaghraby, E.K., Ali, S.A., Abdel-Hady, K. (2004). Characterization of nickel oxide films deposited at different substrate temperatures using spray pyrolysis. J. Cryst. Growth, 262, 424-434.

[29] Pankove, J.I., (1971). Optical Processes in Semiconductors. Prentice-Hall Inc., Englewoord Cliffs, NJ. USA. 
[30] Urbach, F., (1953). The Long-Wavelength Edge of Photographic Sensitivity and of the Electronic Absorption of Solids. Physics Review, 92, 1318-1324.

[31] Li, Q.H., Wan, Q., Liang, Y.X., Wang, T.H. (2004). Electronic transport through individual $\mathrm{ZnO}$ nanowires. Appl. Phys. Lett., 84, 4556-4558.

[32] Zhu, B.L., Zeng, D.W., Wu, J., Song, W.L., Xie, C.S. (2003). Synthesis and gas sensitivity of In-doped ZnO nanoparticles. J. Mater. Sci. Mater. Electron., 14, 521-526.

[33] Zhu, B.L., Xie, C.S., Wu, J., Zeng, D.W., Wang, A.H., Zhao, X.Z., (2006). Influence of $\mathrm{Sb}$, In and $\mathrm{Bi}$ dopants on the response of $\mathrm{ZnO}$ thick films to VOCs. Mater. Chem. Phys., 96, 459-465. 